Supplement of The Cryosphere, 13, 2633-2656, 2019

https://doi.org/10.5194/tc-13-2633-2019-supplement

(C) Author(s) 2019. This work is distributed under

the Creative Commons Attribution 4.0 License.

(c) (1)

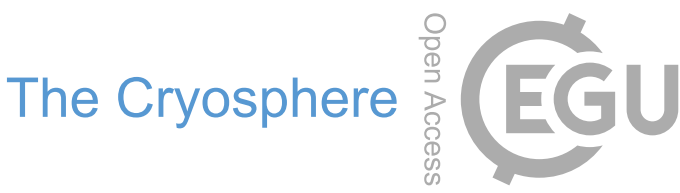

Supplement of

\title{
Ice shelf basal melt rates from a high-resolution digital elevation model (DEM) record for Pine Island Glacier, Antarctica
}

David E. Shean et al.

Correspondence to: David E. Shean (dshean@uw.edu)

The copyright of individual parts of the supplement might differ from the CC BY 4.0 License. 


\section{Supplementary Figures}

MC v2, Rignot et al. (2014)

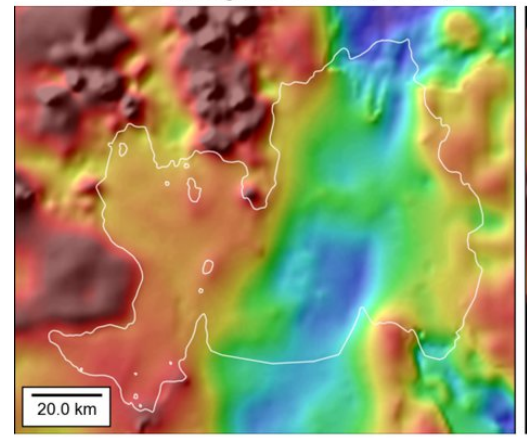

BEDMAP2, Fretwell et al. (2013)

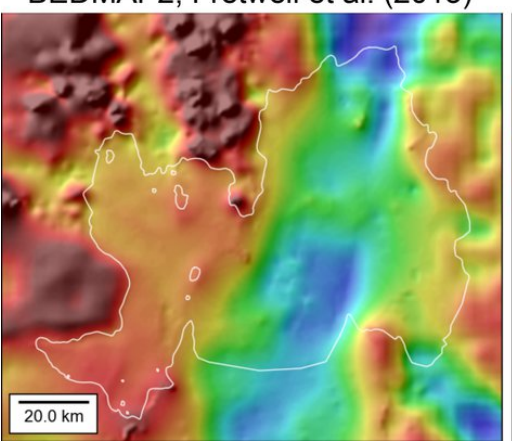

Dutrieux et al. (2014)

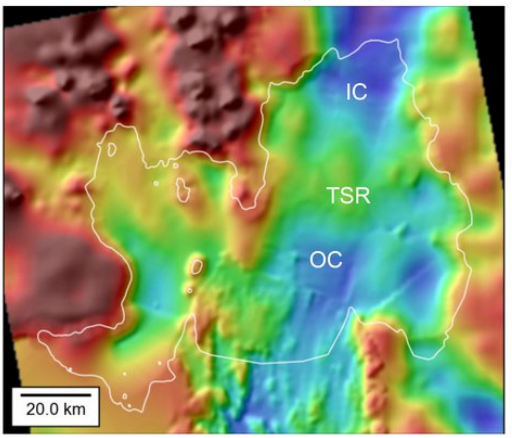

Muto et al. (2016)

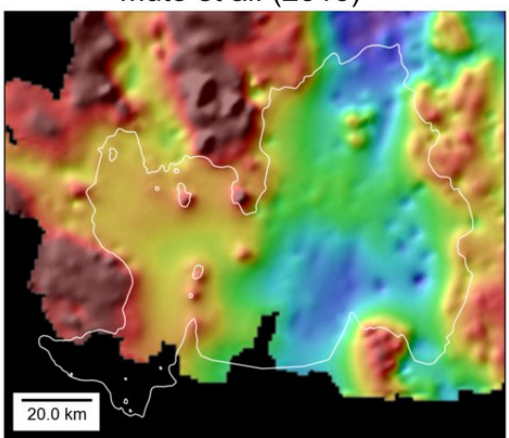

Anisotropic Interpolation

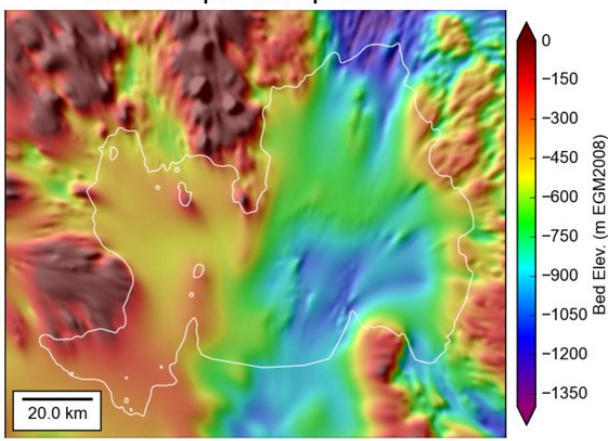

2008-2015 DEM Mean

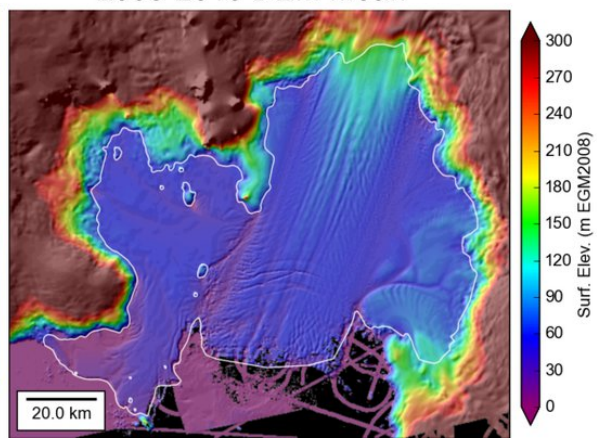

Figure S1: Comparison of available combined bathymetry/bed datasets for PIG ice shelf cavity with mean surface elevation for comparison. See Section 2.6 of main text for details. Top row, center column plot includes labels for "Transverse Seabed Ridge" 5 (TSR), which separates the "Inner Cavity" (IC) and "Outer Cavity" (OC). Note significant differences in inner cavity bathymetry for the different datasets. 

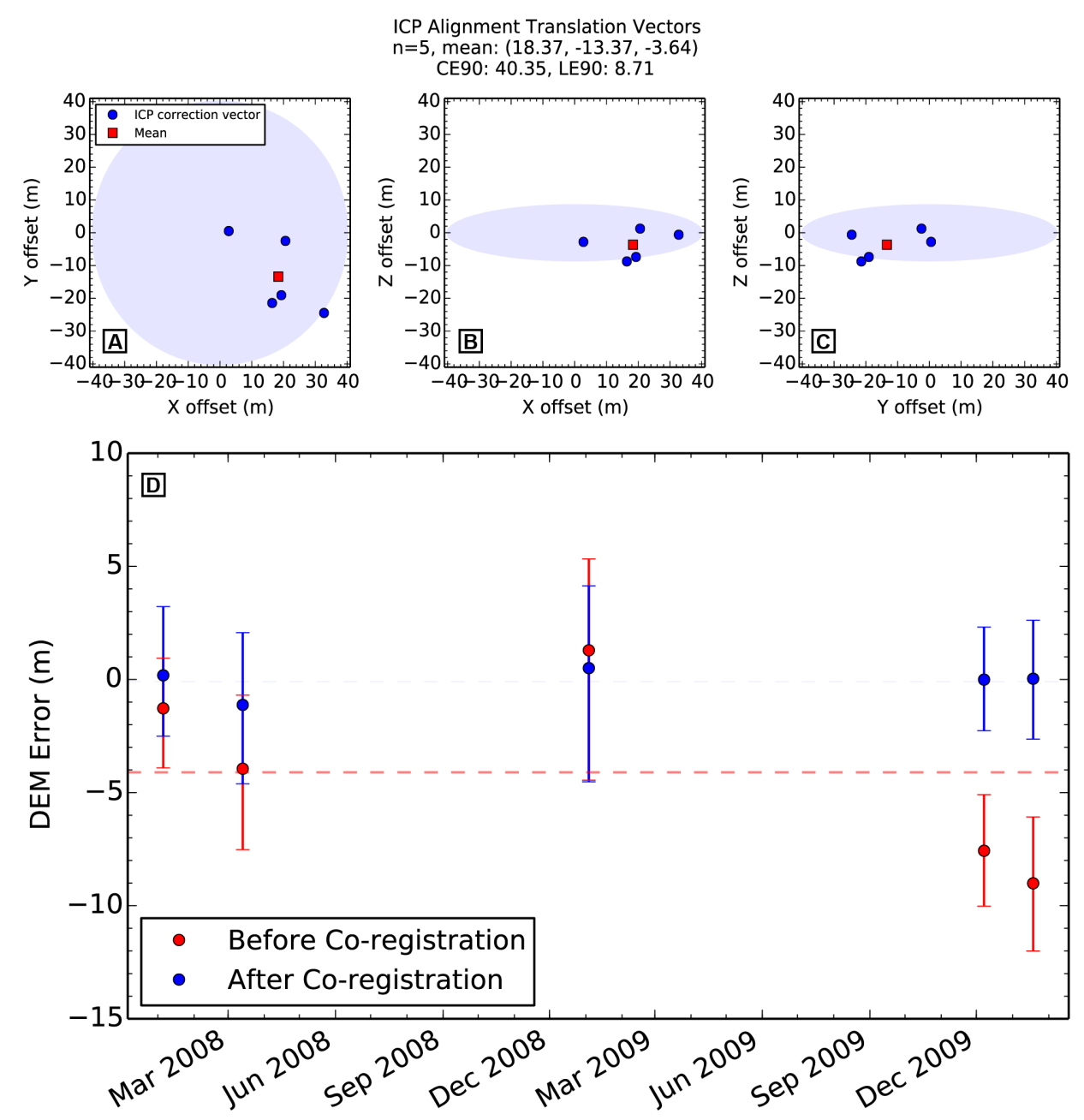

Figure S2: PIG SPIRIT DEM co-registration results. Refer to Figure 3 caption for details. 

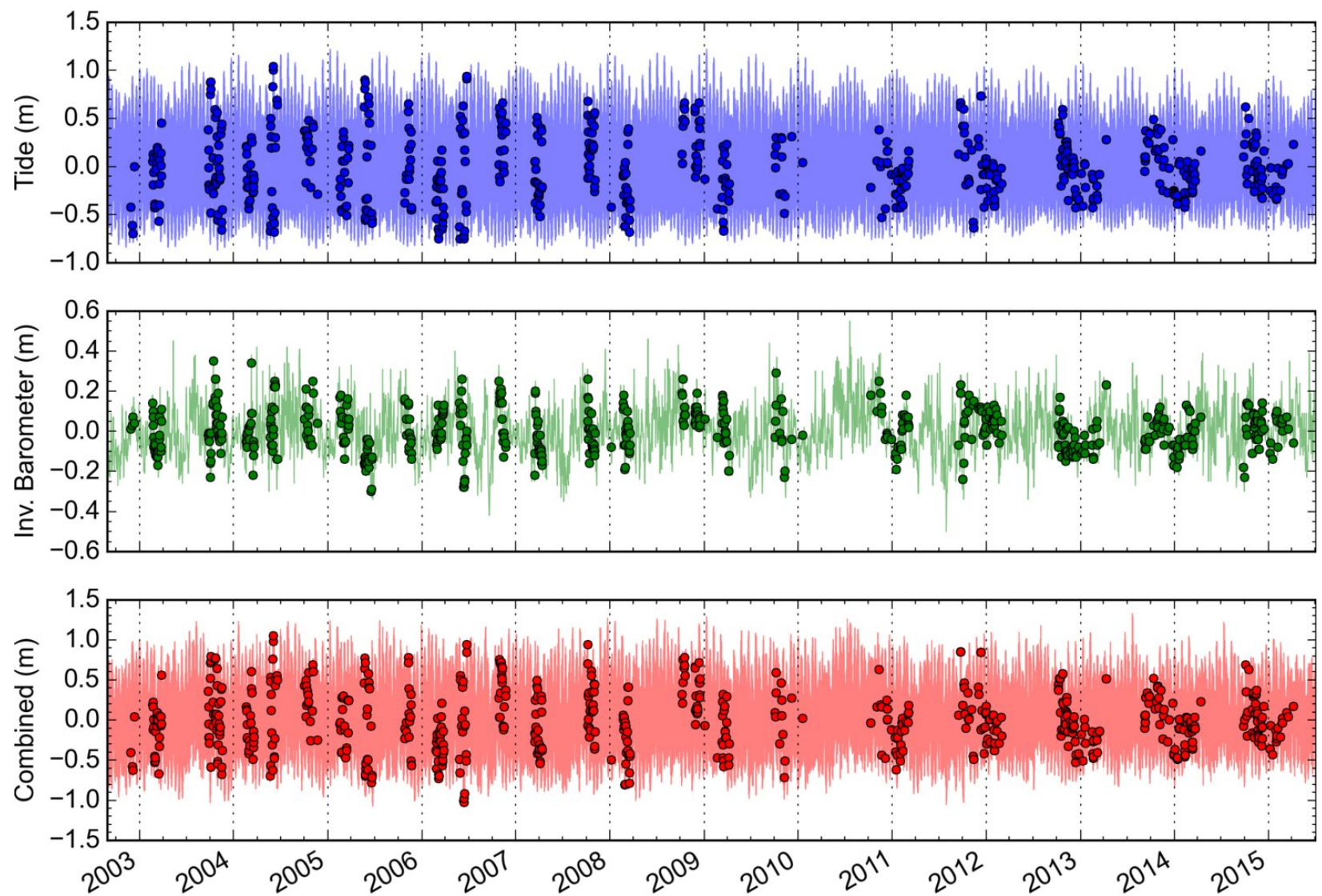

Figure S3: Magnitude of tide and inverse barometer corrections applied to timestamped DEM/altimetry elevation observations (points). 


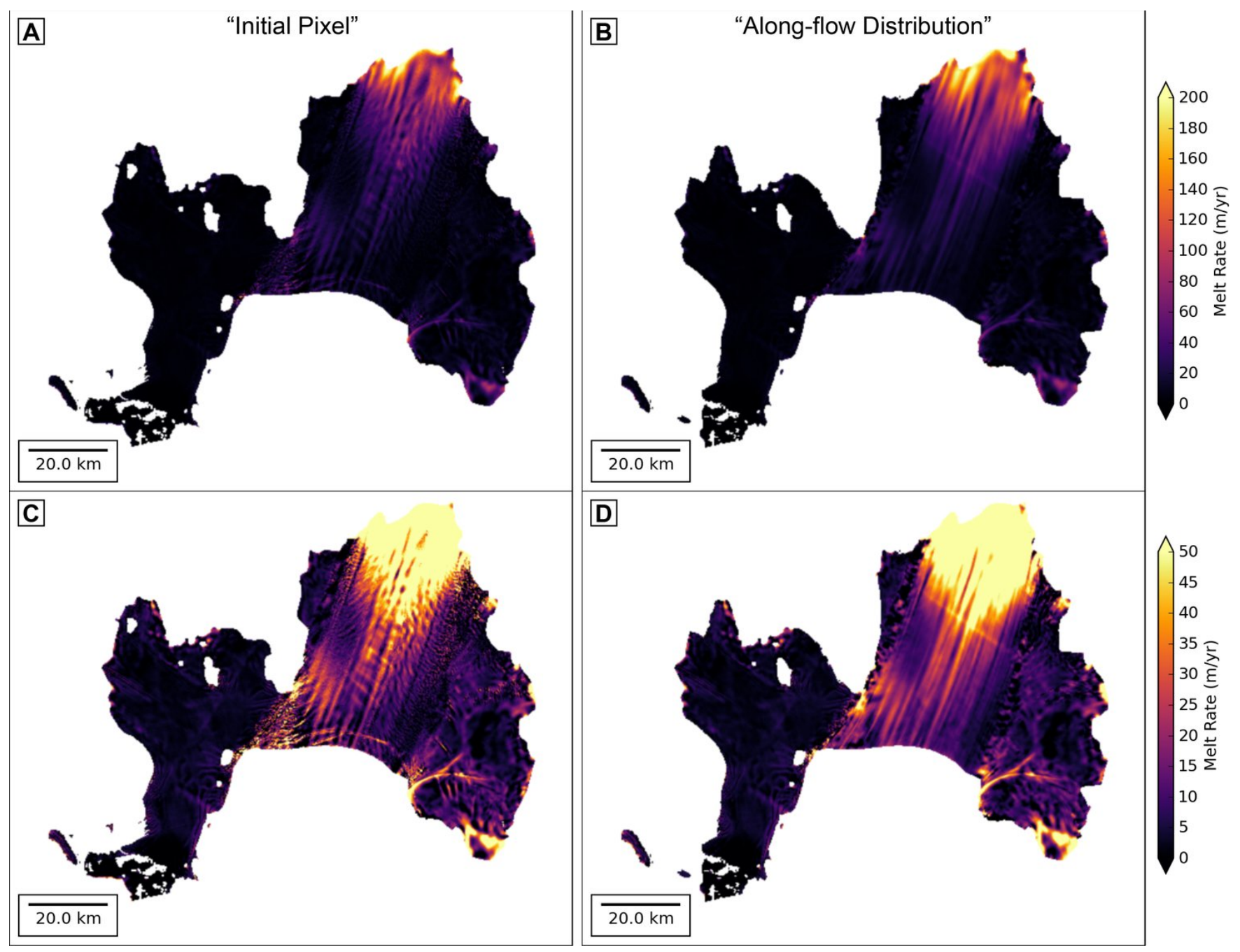

15 Figure S4: Mean 2008-2015 basal melt rates with different colorbar stretch. 

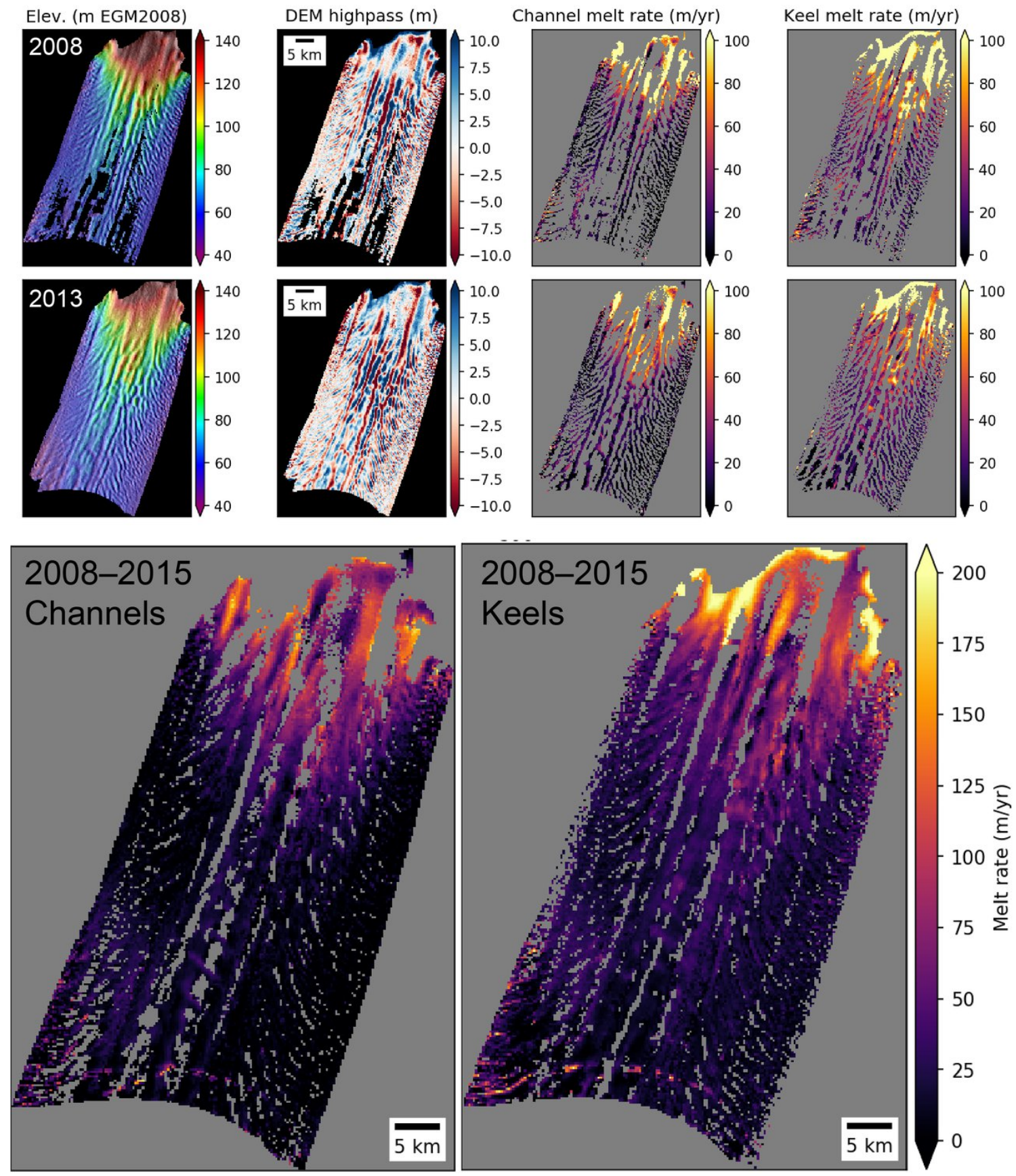

Figure S5: Additional products for channel and keel basal melt rate analysis. See Figure 10 caption in main text. Top row shows initialpixel melt rate products for 2008-2010, second row show initial-pixel melt rate products for 2013-2015. Bottom row shows 2008-2015 composites for channels and keels, with extended color ramp stretch to bring out details over the inner cavity. 